\title{
And Justice for All? There Is More to the Interoperability of Contact Tracing Apps Than Legal Barriers. Comment on "COVID-19 Contact Tracing Apps: A Technologic Tower of Babel and the Gap for International Pandemic Control"
}

Rik Crutzen, $\mathrm{PhD}$

Department of Health Promotion, Care and Public Health Research Institute, Maastricht University, Maastricht, Netherlands

Corresponding Author:

Rik Crutzen, $\mathrm{PhD}$

Department of Health Promotion

Care and Public Health Research Institute

Maastricht University

PO Box 616

Maastricht, $6200 \mathrm{MD}$

Netherlands

Phone: 31433882828

Email: rik.crutzen@maastrichtuniversity.nl

Related Articles:

Comment on: https://mhealth.jmir.org/2020/11/e23194/

Comment in: https://mhealth.jmir.org/2021/5/e26630/

(JMIR Mhealth Uhealth 2021;9(5):e26218) doi: 10.2196/26218

\section{KEYWORDS}

COVID-19; contact tracing; data protection; privacy; interoperability; global health; public health

Du and colleagues [1] have conducted a thorough analysis of legal barriers for realizing the interoperability of contact tracing apps and emphasize the need for developing coordinated solutions to promote safe international travel and global control of the COVID-19 pandemic. Possible options for destroying the technological Tower of Babel are proposed that, in my opinion, are not necessarily needed due to legal barriers and warrant a broader reflection.

First, Du et al [1] note that the region-based development of contact tracing apps, along with the data protection laws used in different countries and regions, has resulted in a disconnection between contact tracing apps. A plea is made for a broader consensus in the international community. Within the European Union (EU), interoperability guidelines for contact tracing apps were already adopted by consensus by the eHealth Network in May 2020 [2]. So far, 22 countries make use of a contact tracing app that is in principle interoperable through a federation gateway [3].

Du et al [1] are partly right in stating that this will only solve the problem within the EU, partly because the GDPR (General Data Protection Regulation) imposes strict limitations on countries outside the EU to process data transfers. In short, other countries need to meet the high standards set by the GDPR in terms of personal data protection (for all individuals within the
EU regardless of citizenship, including refugees and tourists). In other words, the GDPR does not rule out data transfer in principle, but sets high standards [4]. This because the right to protection of personal data is part of the Charter of Fundamental Rights of the EU [5]. Article 8 of the Charter clearly indicates that "everyone has the right to protection of personal data concerning him or her."

Second, Du et al [1] offer a bold proposal: a common contact tracing app that is accepted by all countries and made mandatory for international travelers. Technically, the Google-Apple API (application programming interface) allows governments to work on developing their own contract tracing apps that are interoperable. Although this is not the same as the proposed app, it is a common interface that can be used across countries.

More importantly, even if all legal barriers are addressed when adopting such an interface on a global scale, making a contact tracing app mandatory is too bold a proposal. This is not (only) a legal concern, but (even more so) an ethical concern. Morley and colleagues [6] have synthesized 16 questions concerning factors that should be satisfied in order for a contact tracing app to be ethical. An important factor dictates that downloading and installing such an app should be optional. People should also not be penalized for noncompliance. Morley et al [6] 
acknowledge that these questions are likely to generate disagreement in terms of satisfying and prioritizing factors.

So, I agree with $\mathrm{Du}$ et al [1] on the need for developing coordinated solutions, but this should not only be focused on addressing legal barriers. Instead, such solutions should make optimal use of readily available technology and take ethical concerns seriously. In a raging pandemic, it might be alluring to take an everything-but-the-kitchen-sink approach and focus solely on controlling COVID-19. However, especially in a crisis, this "is dangerous when it ignores the real costs, including serious and long-lasting harms to fundamental rights and freedoms" [6]. This is what makes them fundamental.

\section{Conflicts of Interest}

RC serves as chair of the Task Force Behavioral Sciences of the Dutch Ministry of Health, Welfare and Sport, which advises on the development, implementation, and evaluation of digital solutions that contribute to the control of COVID-19.

\section{References}

1. Du L, Raposo VL, Wang M. COVID-19 Contact Tracing Apps: A Technologic Tower of Babel and the Gap for International Pandemic Control. JMIR Mhealth Uhealth 2020 Nov 27;8(11):e23194. [doi: 10.2196/23194]

2. Interoperability guidelines for approved contact tracing mobile applications in the EU. eHealth Network. 2020. URL: https:/ lec.europa.eu/health/sites/health/files/ehealth/docs/contacttracing mobileapps guidelines en.pdf [accessed 2021-04-16]

3. Explanatory memorandum on temporary law notification application Covid-19. Dutch Ministry of Health, Welfare and Sport. 2020. URL: https://www.rijksoverheid.nl/documenten/publicaties/2020/11/20/nota-van-toelichting [accessed 2021-04-16]

4. Regulation (EU)/679 of the European Parliament and of the Council of 27 April on the protection of natural persons with regard to the processing of personal data and on the free movement of such data, and repealing Directive 95/46/EC. European Parliament and Council. 2016. URL: https://eur-lex.europa.eu/legal-content/EN/TXT/?uri=CELEX:02016R0679-20160504 [accessed 2021-04-16]

5. Charter of Fundamental Rights of the European Union. European Union. 2012. URL: https://eur-lex.europa.eu/legal-content/ EN/TXT/?uri=CELEX:12012P/TXT [accessed 2021-04-16]

6. Morley J, Cowls J, Taddeo M, Floridi L. Ethical guidelines for COVID-19 tracing apps. Nature 2020 Jun;582(7810):29-31. [doi: 10.1038/d41586-020-01578-0] [Medline: 32467596]

\section{Abbreviations \\ API: application programming interface \\ EU: European Union \\ GDPR: General Data Protection Regulation}

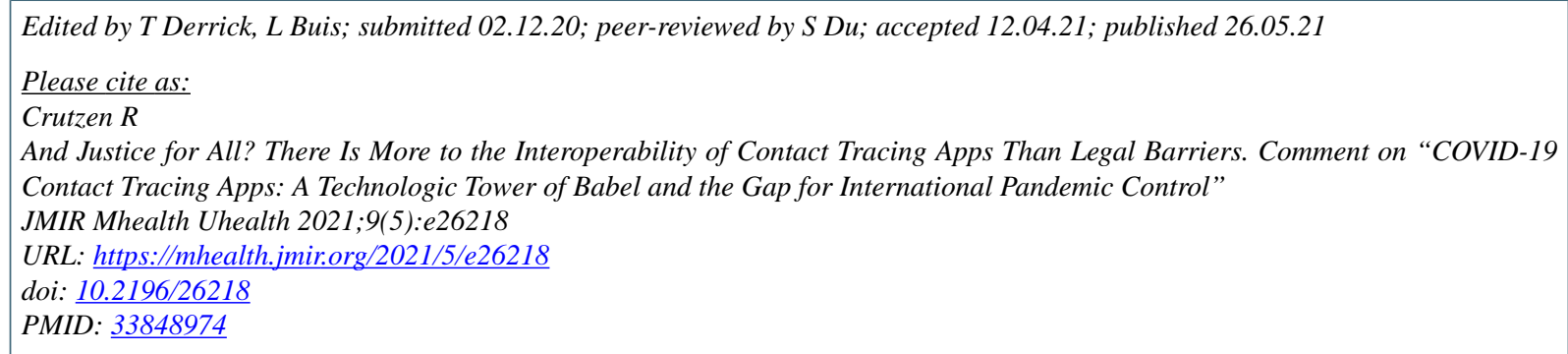

CRik Crutzen. Originally published in JMIR mHealth and uHealth (https://mhealth.jmir.org), 26.05.2021. This is an open-access article distributed under the terms of the Creative Commons Attribution License (https://creativecommons.org/licenses/by/4.0/), which permits unrestricted use, distribution, and reproduction in any medium, provided the original work, first published in JMIR mHealth and uHealth, is properly cited. The complete bibliographic information, a link to the original publication on https://mhealth.jmir.org/, as well as this copyright and license information must be included. 